\title{
Upper Thoracic Myelopathy Caused by Delayed Neck Extensor Weakness in Myotonic Dystrophy
}

\author{
Han Kyeong Son, M.D., Young Sun Cha, M.D., Hwi Suh, M.D., \\ Chang-Seok Ki, M.D.,Ph.D. ${ }^{1}$, Yong Beom Shin, M.D., Ph.D. \\ Department of Rehabilitation Medicine, Pusan National University School of Medicine, Busan 602-739, \\ ${ }^{1}$ Department of Laboratory Medicine \& Genetics, Samsung Medical Center, \\ Sungkyunkwan University School of Medicine, Seoul 135-710, Korea
}

Myotonic dystrophy is the most common autosomal dominant myopathy in adults. Our patient, a 41 year-old female suffering from myotonic muscular dystrophy, developed upper thoracic myelopathy due to hypertrophy of the ligamentum flavum and the posterior longitudinal ligament. She had a typical hatchet face and ptosis with "head hanging forward" appearance caused by neck weakness. Motor weakness, sensory changes and severe pain below T4 level, along with urinary incontinence began 3 months ago. Genetic and electrodiagnostic studies revealed myotonic dystrophy type 1 . Magnetic resonance imaging of the spine showed loss of cervical lordosis and spinal cord compression due to hypertrophied ligamentum flavum and posterior longitudinal ligament at $\mathrm{Tl}$ to T3 level. We concluded that her upper thoracic myelopathy was likely related to the thickness of the ligamentum flavum and posterior longitudinal ligament due to repetitive mechanical stress on her neck caused by neck muscle weakness with myotonic dystrophy.

Key Words Myotonic dystrophy, Neck weakness, Thoracic myelopathy

\section{INTRODUCTION}

Myotonic dystrophy is the most common form of muscular dystrophy affecting adults. Myotonic dystrophy affects at least 1 in 8,000 people worldwide. It is an inherited condition that is autosomal dominant disease. ${ }^{1}$

Received January 31, 2011; Accepted October 10, 2011

Corresponding author: Yong Beom Shin

Department of Rehabilitation Medicine, Pusan National University School of Medicine,10, Ami-dong 1ga, Seo-gu, Busan 602-739, Korea Tel: +82-51-240-7485, Fax: +82-51-247-7485, E-mail: yi0314@gmail.com (c) This is an open-access article distributed under the terms of the Creative Commons Attribution Non-Commercial License (http:// creativecommons.org/licenses/by-nc/3.0) which permits unrestricted noncommercial use, distribution, and reproduction in any medium, provided the original work is properly cited.

Copyright $\odot 2012$ by Korean Academy of Rehabilitation Medicine
General symptoms and signs usually present between the ages of 10 to 30 and the predominant symptoms are distal muscle weakness, leading to difficulty performing tasks requiring fine dexterity of the hands, foot drop, particularly affecting ankle dorsiflexors, and also involving proximal muscles. Muscle weakness progresses slowly however, neck weakness may be a prominent sign in several types of neuromuscular diseases including myopathies, neuromuscular junction disorders and neurogenic conditions. ${ }^{2,3}$ With the progression of cervical spinal deformity caused by weakness of the the neck extensor muscles, the mechanical stress applied to the anterior and posterior aspectsof the spinal cord eventually increases. Loss of alignment of the cervical spine and spinal cord may contribute to the development 
of myelopathy. ${ }^{4}$ Here we report a rare case of upper thoracic myelopathy secondary to hypertrophies of the ligamentum flavum and the posterior longitudinal ligament in a 41 year-old woman who had been diagnosed with myotonic dystrophy type 1 .

\section{CASE REPORT}

A 41 year-old woman was referred to our rehabilitation clinic with progressive weakness of the lower extremi-

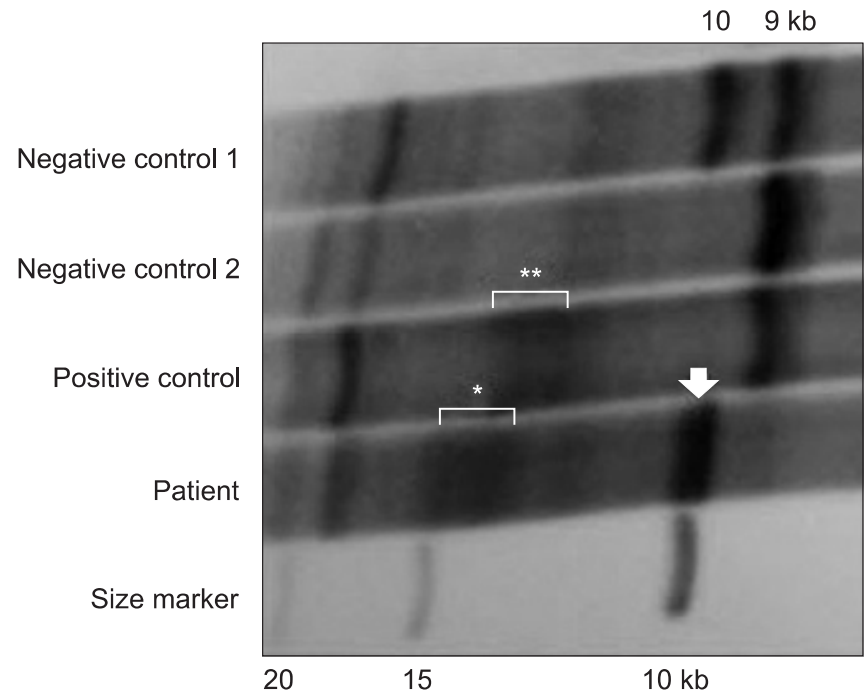

Fig. 1. Southern blot analysis of the DMPK gene shows a normal $10 \mathrm{~kb}$ band (arrow) and an abnormal 13-15 $\mathrm{kb}$ band corresponding to 900-1666 CTG expansion (*). Negative control 1 and 2 have heterozygous 9 and $10 \mathrm{~kb}$ bands and a homozygous $9 \mathrm{~kb}$ band, respectively, while the positive control has a normal $9 \mathrm{~kb}$ band and an abnormal $12.5-13.5 \mathrm{~kb}$ band $(* *)$. ties, severe pain and urinary incontinence for the last 3 months. Prior to this, she could walk with an assisting device, such as a walker, but her lower extremities grew weaker and consequently she could not stand without assistance.

Facial jaw muscle atrophy, ptosis, and a "hatchet-like" face were observed. She had developed progressive weakness of the neck and paraspinal muscles for 3 years and she could no longer support her head without it hanging forward.

Severe weakness of the neck flexor (grade 2 using the Medical Research Council Scale) and extensor (grade 2-/5) muscles with mild to moderate weakness of both upper extremities (grade 3 or 4) were observed. There was no voluntary movement in either lower extremity. The results of sensory functional examinations were as follows: above both $\mathrm{T} 3$ dermatomes: $2 / 2$ (right/left) T4 to T10 dermatomes: 1/2 below T11: 0/2. Babinski and Chaddock signs were positive, bilaterally. Voluntary anal contractions, clitocavernous reflexes or anal senses were not observed. Finally, we diagnosed the condition as an upper thoracic spinal cord injury.

She denied having underlying chronic diseases, such as hypertension or diabetes mellitus, nor any physical traumatic history for the last year. Her father's gait was disabled during his life and her 39 year-old brother suffered with progressive weakness and muscle atrophy of the extremities and could no longer walk without assistance. In electrophysiologic studies, both ulnar nerve somatosensory evoked potentials (SEPs) were normal but were not recorded in both tibial nerves. Nerve conduction studies were within normal limits. However, needle elec-

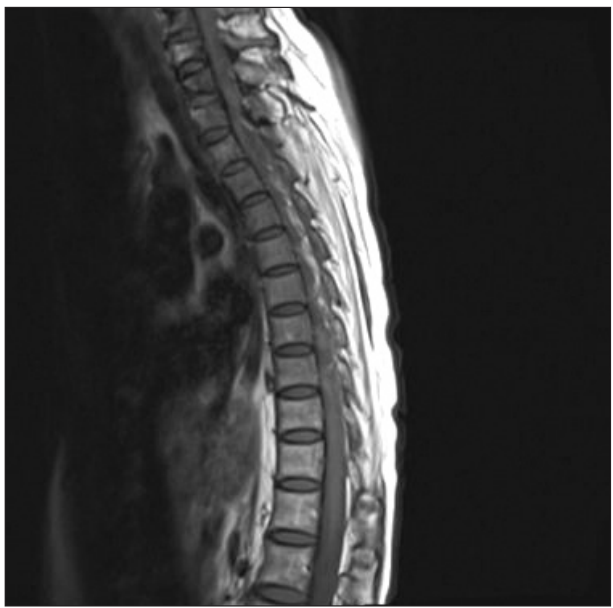

T1WI

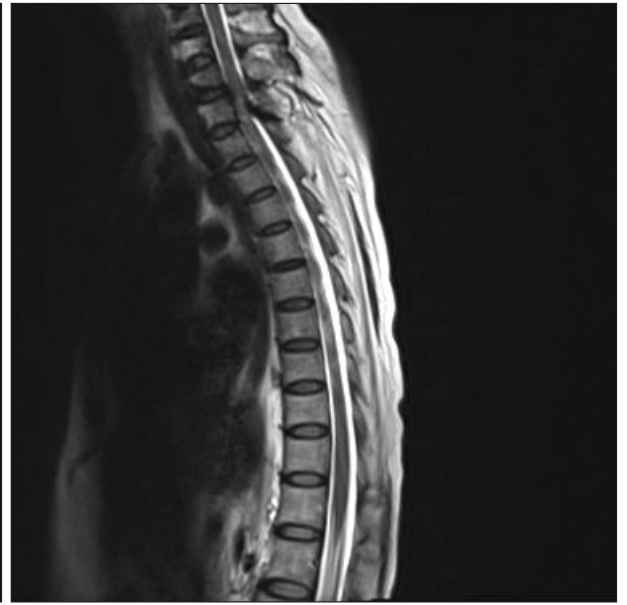

$\mathrm{T} 2 \mathrm{WI}$
Fig. 2. Sagittal view of the spinal MRI showing spinal cord compression by thickness of posterior longitudinal ligament and ligamentum flavum at the level of T1 to T3. 


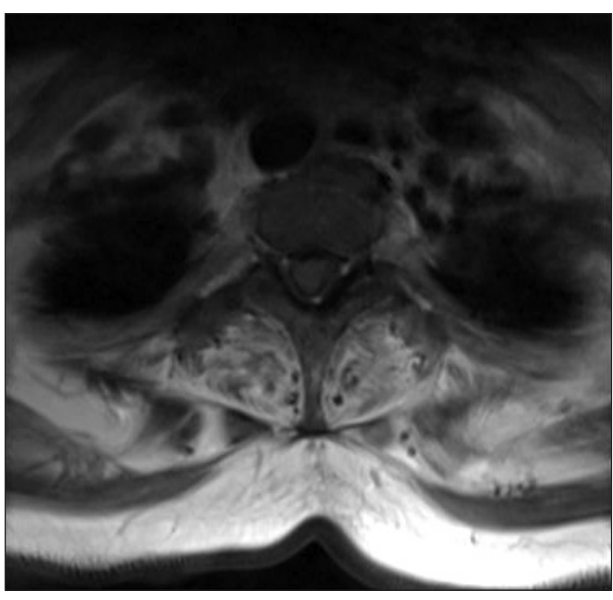

T1WI

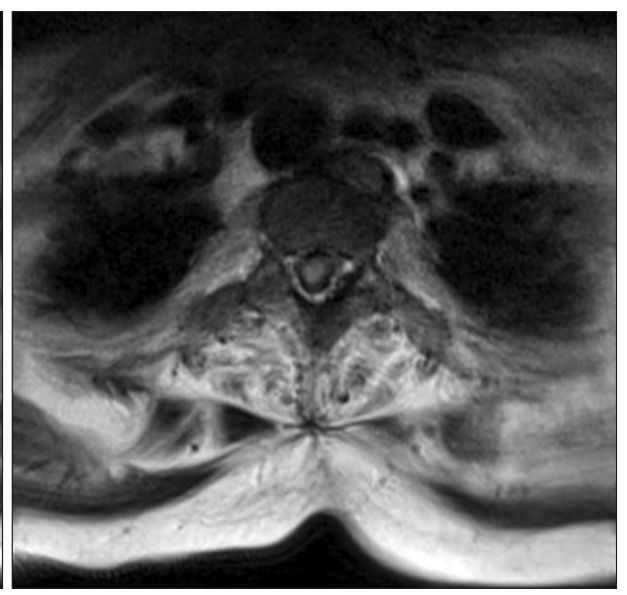

$\mathrm{T} 2 \mathrm{Wl}$
Fig. 3. Axial view of the spinal MRI demonstrating thecal sac indentation and abnormal signal changes of the spinal cord by epidural fibromatosis derived from hypertrophied ligamentum flavum at the T2 level. tromyographic examinations of the upper extremity and cervical paraspinal muscles showed short duration, small amplitude, and polyphasic motor unit action potentials with myotonic discharges.

Molecular genetic analysis of the $D M P K$ gene showed an abnormal CTG expansion (approximately 900-1666 CTG repeats) that were compatible with myotonic dystrophy type 1 (DM1) (Fig. 1).

We also carried out magnetic resonance imaging studies of the spine to find the cause of the recent aggravation of lower limb weakness and urinary incontinence. Magnetic resonance imaging of the spine showed a loss of cervical lordosis and anterior and posterior thecal sac indentation by epidural lesion derived from the hypertrophied ligamentum flavum and the posterior longitudinal ligament with a high signal intensity of the spinal cord in a T2-weighted image (Fig. 2, 3).

By analyzing the results of all diagnostic examinations, we concluded that hypertrophy of the ligamentum flavum and the posterior longitudinal ligament led to upper thoracic myelopathy by repetitive mechanical stress due to weakness of neck muscles in a patient with myotonic dystrophy.

\section{DISCUSSION}

In many neuromuscular diseases, weakness of the neck flexors is more common than weakness of the extensors. The relative rarity of predominant neck extensor weakness in patients with neuromuscular disorders has led several authors to describe a 'floppy head' or 'dropped head' syndrome defined as weakness of the neck extension against gravity with or without involvement of the neck flexion. ${ }^{3}$

In a case of dropped head syndrome, the patient's head hangs forward when the body is in the upright or sitting position. Although commonly considered a benign condition by itself, patients ordinarily complain of head drop, neck pain, and limited activities because the patient can only look downward. ${ }^{5}$ The dropped head is primarily due to excessive tension in the anterior cervical muscles associated with weakness or atrophy of the posterior cervical muscles. These can cause deformities and affect the biomechanics of normal cervicothoracic curvatures.

Thickening of the ligamentum flavum may be due to fibrosis of the ligaments secondary to degenerative changes or aging. ${ }^{6}$ As a result, collagen hyperplasia and hypertrophy may occur. The etiology and pathophysiology of ligamentum flavum hypertrophy remain controversial, but mechanical factors, such as repetitive local strain, are known as major factors. ${ }^{7}$ Moreover, ossification or hypertrophy of the ligamentum flavum may occur in combination with ossification of the posterior longitudinal ligament, which then aggravates myelopathy if present. ${ }^{8}$ Guo et al. ${ }^{9}$ described ossification of the ligamentum flavum as most frequently occurring in the lower-thoracic region (T10-T12) because this region is transitioning from the thoracic to lumbar spine, where there is less anatomic protection from the rib cage. They also reported that the second most common region is the upper thoracic spine (T1-T4) because thoracic kyphosis would result in stretching of the spinal cord over the lesion and this is the part of the spinal cord 
with the poorest collateral circulation. The anatomy of the cervicothoracic junction is unique in that, along with the transition from the mobile cervical spine to the rigid thoracic spine, there is also a change from cervical lordosis to thoracic kyphosis. ${ }^{10}$ In this case, myelopathy was found at the level of T1-T2 in the magnetic resonance image therefore, we could assume that excessive mechanical stress to the region of transition from cervical lordosis to thoracic kyphosis due to weakness of neck muscles led to hypertrophies of the ligamentum flavum and the posterior longitudinal ligament, finally causing upper thoracic myelopathy.

As clinical weakness of the proximal and paraspinal muscles could be present in patients in the late stage of classic DM1, there would be many chances to be mistaken for important neurological deterioration signs induced by muscle weakness. ${ }^{1}$ In this case, our patient was living in an inadequate nursing facility due to financial constraints and had not had the appropriate medical examinations and treatment. For these reasons, no one noticed that repetitive mechanical stress to her neck resulted in a spinal cord injury.

Through this case report, we have to consider the possibility of cervical or cervicothoracic myelopathy secondary to delayed neck muscle weakness in myotonic dystrophy patients with unexpected weakness progression. In conclusion, regular follow-ups about the clinical course of muscle weakness and a timely decision to prevent additional disability using a device such as a neck collar or the possibility of surgical procedures are needed for patients with these conditions.

\section{ACKNOWLEDGEMENTS}

This work was supported by a 2-Year Research Grant of Pusan National University.

\section{REFERENCES}

1. Cho DH, Tapscott SJ. Myotonic dystrophy: emerging mechanisms for DM1 and DM2. Biochim Biophys Acta 2007; 1772: 195-204

2. Turner C, Hilton-Jones D. The myotonic dystrophies: diagnosis and management. J Neurol Neurosurg Psychiatry 2010; 81: 358-367

3. Goh KJ, Wong KT, Tan CT. Myopathic dropped head syndrome: a syndrome of mixed aetiology. J Clin Neurosci 2000; 7: 334-336

4. Uchida K, Nakajima H, Sato R, Yayama T, Mwaka ES, Kobayashi S, Baba H. Cervical spondylotic myelopathy associated with kyphosis or sagittal sigmoid alignment: outcome after anterior or posterior decompression. J Neurosurg Spine 2009; 11: 521-528

5. Nakanishi K, Taneda M, Sumii T, Yabuuchi T, Iwakura N. Cervical myelopathy caused by dropped head syndrome. Case report and review of the literature. J Neurosurg Spine 2007; 6: 165-168

6. Jayakumar PN, Devi BI, Bhat DI, Das BS. Thoracic cord compression due to ossified hypertrophied ligamentum flavum. Neurol India 2002; 50: 286-289

7. Giulioni M, Zucchelli M, Damiani S. Thoracic myelopathy caused by calcified ligamentum flavum. Joint Bone Spine 2007; 74: 504-505

8. Al-Orainy IA, Kolawole T. Ossification of the ligament flavum. Eur J Radiol 1998; 29: 76-82

9. Guo JJ, Luk KD, Karppinen J, Yang H, Cheung KM. Prevalence, distribution, and morphology of ossification of the ligamentum flavum: a population study of one thousand seven hundred thirty-six magnetic resonance imaging scans. Spine (Phila Pa 1976) 2010; 35: 51-56

10. Ames CP, Bozkus MH, Chamberlain RH, Acosta FL Jr, Papadopoulos SM, Sonntag VK, Crawford NR. Biomechanics of stabilization after cervicothoracic compression-flexion injury. Spine (Phila Pa 1976) 2005; 30: 1505-1512 